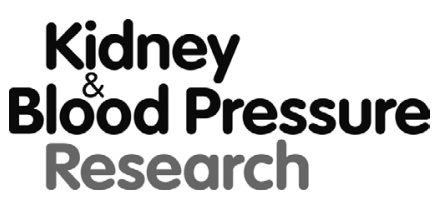

Kidney Blood Press Res 2018;43:1053-1064

DOI: 10.1159/000491056

Published online: 2 July, 2018

Accepted: 20 June, 2018

This article is licensed under the Creative Commons Attribution-NonCommercial-NoDerivatives 4.0 International License (CC BY-NC-ND) (http://www/kargercom/Services/OpenAccessLicense). Usage and distribution for commercial purposes as well as any distribution of modified material requires written permission.

\title{
Adenine-Induced Chronic Renal Failure in Rats: A Model of Chronic Renocardiac Syndrome with Left Ventricular Diastolic Dysfunction but Preserved Ejection Fraction
}

\author{
Pavlos Kashioulis $^{a} \quad$ Jaana Lundgren ${ }^{a} \quad$ Emman Shubbar $^{a} \quad$ Lisa Nguya,b Aso Saeed ${ }^{a}$ \\ Cecilia Wallentin Guron ${ }^{\mathrm{a}}$ Gregor Guron ${ }^{\mathrm{a}}$ \\ aDepartment of Molecular and Clinical Medicine, Institute of Medicine, the Sahlgrenska Academy at \\ the University of Gothenburg, Gothenburg, bepartment of Physiology, Institute of Neuroscience and \\ Physiology, the Sahlgrenska Academy at the University of Gothenburg, Gothenburg, Sweden
}

\section{Key Words}

Chronic kidney disease - Adenine - Hypertension - Left ventricular hypertrophy - Diastolic dysfunction

\begin{abstract}
Background/Aims: Cardiovascular disease is the major cause of death in patients with chronic kidney disease (CKD). Rats with adenine-induced chronic renal failure (ACRF) develop severe renal insufficiency and metabolic abnormalities that closely resemble those in patients with uremia. The aim of the present study was to determine left ventricular (LV) morphology and function in rats with ACRF. Methods: Male Sprague-Dawley rats received either chow containing adenine or were pair-fed an identical diet without adenine (controls, C). After 9-13 weeks animals were anesthetized with isoflurane and cardiac function was assessed both by echocardiography and by LV catheterization. Results: Rats with ACRF showed increases in serum creatinine $(323 \pm 107$ vs. $33 \pm 5 \mu \mathrm{M}, \mathrm{P}<0.05)$, mean arterial pressure $(115 \pm 6$ vs. $106 \pm 7$ $\mathrm{mmHg}, \mathrm{P}<0.05)$ and $\mathrm{LV}$ weight $(3.4 \pm 0.3$ vs. $2.5 \pm 0.2 \mathrm{mg} / \mathrm{kg}, \mathrm{P}<0.05)$ vs. controls. Rats with ACRF had reduced early diastolic tissue Doppler velocities in the LV, enlarged left atrial diameter $(4.8 \pm 0.8$ vs. $3.5 \pm 0.4 \mathrm{~mm}, \mathrm{P}<0.05)$ and elevated LV end-diastolic pressure $(15 \pm 5 \mathrm{vs} .8 \pm 1 \mathrm{mmHg}$, $\mathrm{P}<0.01)$. Cardiac output was increased in ACRF rats $(211 \pm 66$ vs. $149 \pm 24 \mathrm{ml} / \mathrm{min}, \mathrm{P}<0.05)$ and systolic function preserved. In the LV of ACRF rats there were statistically significant $(P<0.05)$ increases in cardiomyocyte diameter, proliferation and apoptosis, while there was no difference between groups in fibrosis. Conclusion: Rats with ACRF develop LV hypertrophy and diastolic
\end{abstract}




\section{Kidney Blood Pressure Research}

Kidney Blood Press Res 2018;43:1053-1064

\begin{tabular}{l|l}
\hline DOI: $10.1159 / 000491056$ & (C) 2018 The Author(s). Published by S. Karger AG, Basel
\end{tabular}

Published online: 2 July, 2018

www.karger.com/kbr

1054

dysfunction while systolic performance was preserved. There was an increased hypertrophy and apoptosis of cardiomyocytes in the LV of ACRF rats. The cardiac abnormalities in ACRF rats resemble those in patients with CKD in which heart failure with preserved ejection fraction is common. Hence, this experimental model is well suited for studying pathophysiological mechanisms in chronic renocardiac syndromes.

\section{Introduction}

Cardiovascular (CV) disease is the major cause of morbidity and mortality in patients with chronic kidney disease (CKD) [1]. There is a graded and inverse relationship between estimated glomerular filtration rate (GFR) and CV risk that is apparent already when GFR falls below $60 \mathrm{ml} / \mathrm{min} / 1.73 \mathrm{~m}^{2}$ [2]. The majority of CKD patients die from CV events before developing end-stage renal disease [3]. Interestingly, traditional CV risk factors such as hypertension and hyperlipidemia do not appear to be equally important in CKD patients as in the general population [4]. Instead, non-traditional risk factors specifically related to CKD, such as vascular calcifications, hypervolemia, and electrolyte disorders may be more important [4]. A relevant animal model would be of much use to investigate the pathophysiological mechanisms leading to CV disease in CKD.

For this purpose, we have developed a model of severe chronic renal failure in SpragueDawley rats by feeding animals with chow supplemented with adenine [5], i.e. adenineinduced chronic renal failure (ACRF). These rats develop tubulointerstitial kidney injury [6] and a pronounced reduction in GFR to about $10 \%$ of values in healthy controls [5, 7]. In addition, rats with ACRF develop hypertension, disordered mineral metabolism with secondary hyperparathyroidism, elevated oxidative stress, and an increased aortic pulse wave velocity (PWV) [5]. Due to its resemblance with the uremic syndrome in patients, we consider this model promising for examining pathophysiological mechanisms that cause CV disease in CKD.

The aim of the present study was to determine the effects of ACRF on cardiac morphology and function in rats and to examine mechanisms causing cardiac abnormalities. We hypothesized that this animal model could be well suited for analyzing pathophysiological mechanisms in chronic renocardiac syndromes.

\section{Materials and Methods}

\section{General Procedures}

Fifty-six male Sprague-Dawley rats (Harlan, Horst, The Netherlands) weighing $\sim 300 \mathrm{~g}$ were used and housed in rooms with a controlled temperature of $24-26^{\circ} \mathrm{C}$ and a $12: 12$-h dark-light cycle. Chronic renal failure was produced by feeding animals with chow containing adenine as previously described [5] using a modification of protocols employed by other investigators [7-9]. Longitudinal data on body weight, water intake, plasma creatinine concentrations and blood pressure (BP) in this model have been published previously [5]. At study start (i.e., day one of the study), all animals were randomized to, and provided with, standard pelleted rat chow containing adenine (adenine-induced ACRF, $\mathrm{n}=28$ ) or identical chow without adenine (pair-fed controls, $\mathrm{n}=28$ ). The chow (R34, Lantmännen, Kimstad, Sweden) contained $0.63 \%$ phosphorous, $0.74 \%$ calcium, $0.53 \%$ potassium, and $0.22 \%$ sodium. The concentration of adenine in the chow was $0.5 \%$ for the first 3 weeks followed by $0.3 \%$ for 2 weeks and $0.15 \%$, thereafter, until animals were sacrificed. As pilot studies revealed a reduced food intake in animals consuming adenine-containing chow, controls were pair-fed and received their daily ration of chow once daily in the morning. Rats had free access to tap water throughout the study. Chemicals were from Sigma (St. Louis, MO, USA) if not stated otherwise. All experiments were approved by the regional ethics committee in Gothenburg, Sweden. 


\section{Kidney Blood Pressure Research}

Kidney Blood Press Res 2018;43:1053-1064

\begin{tabular}{l|l}
\hline DOI: 10.1159/000491056 & (C) 2018 The Author(s). Published by S. Karger AG, Base
\end{tabular}

Published online: 2 July, 2018 www.karger.com/kb

Kashioulis et al.: Left Ventricular Function in Rats with Adenine-Induced Chronic Renal

Failure

\section{Study group A ( $n=10$ per group), LV function and fibrosis}

Echocardiography (group A). Echocardiography was performed 9 weeks after study start. Rats were anesthetized with isoflurane (Pharmacia \& Upjohn, Stockholm, Sweden) mixed with air during spontaneous breathing by using a vaporizer (Univentor-1200, Agnthos, Lidingö, Sweden). For induction and maintenance of anesthesia isoflurane concentrations of approximately $5 \%$ and $1.5 \%$ (vol/vol), respectively, were used. The thorax was carefully shaved and rats were placed on an electrical heating pad to maintain a rectal temperature of $37^{\circ} \mathrm{C}$ throughout. After the echocardiographic examination rats were allowed to wake up and were returned to their cages. Echocardiography was performed using a high-frequency $12-\mathrm{MHz}$ phased-array transducer (P12-5, Philip Medical System, Best, The Netherlands) connected to an ultrasound system (HDI 5000 ATL, Philip Medical System) as previously described [10]. Short axis 2-D views of the left ventricle (LV) at the papillary muscle level were used to obtain M-mode targeted recordings. Stroke volume was determined by pulsed wave Doppler obtained from the five-chamber apical view. Apical four chamber views were obtained for Doppler recordings of mitral blood flow velocities, rendering E (during early filling) and A (during atrial contraction). In addition, tissue velocities were registered at the basal lateral, and basal septal, left ventricular walls during peak systole (s), early diastole (e) and at atrial contraction (a). Left ventricular end-diastolic diameter (LVEDd), LV end-systolic diameter (LVESd), and LV wall dimensions were measured in accordance with the leading-edge method of the American Society of Echocardiography [11]. Fractional shortening (FS) was calculated as FS = [(LVEDd - LVESd) $/$ LVEDd] $\times 100$.

Data were stored on an optical disk and analyzed offline with software (Echo-Pac, Vingmed, Horten, Norway) by one investigator (C. W. G.) blinded to the animals' identity. Average values for each variable were based on analyses of at least three consecutive cardiac cycles.

Left ventricular pressures and plasma analyses (group A). Experiments were performed 12-13 weeks after study start as previously described [12]. Rats were anaesthetized with isoflurane and rectal temperature was kept at $37^{\circ} \mathrm{C}$ throughout. Isotonic saline was infused throughout in a volume of $6 \mathrm{ml} / \mathrm{kg} / \mathrm{h}$ to replace fluid losses. Through the right femoral artery and left carotid artery two ultra-miniature fiber optic pressure sensors (Samba preclin 420, sensor diameter $0.42 \mathrm{~mm}$, Harvard Apparatus Ltd., Edenbridge, Kent, UK) were placed in the distal abdominal aorta at the level of the aortic bifurcation, and in the ascending aorta immediately above the aortic valve. These sensors were used for aortic pulse wave analysis and measurements of aortic PWV and LV pressures applying a sampling frequency of $1000 \mathrm{~Hz}$. The results on aortic pulse wave analysis and PWV from these experiments have previously been published [12]. In the present study only BP data from the ascending aorta and the $\mathrm{LV}$ will be presented. A third arterial catheter (PE 50) was placed in the left femoral artery for continuous BP monitoring throughout. Immediately after catheterization of the left femoral artery a blood sample of approximately $0.4 \mathrm{ml}$ was taken and replaced by an equivalent volume of $4 \%$ bovine serum albumin in isotonic saline. Following centrifugation plasma was stored at $-20^{\circ} \mathrm{C}$ until analyzed. After a 15 min equilibration period, baseline recordings of aortic BPs were performed during 5 minutes. Subsequently, the proximal aortic pressure sensor was gently inserted into the LV for recording of pressure. Thereafter, rats were killed by an overdose of pentobarbital sodium and the heart was immediately excised, separated into the $\mathrm{LV}$ and the free wall of the right ventricle, and weighed.

Aortic and LV pressure data were collected and analyzed by the Biopac MP 150 system (Biopac Systems, Santa Barbara, CA, USA) using the data acquisition software AcqKnowledge. From the data recorded, heart rate, systolic BP, MAP, diastolic BP, and pulse pressure were extracted in real-time. Left ventricular pressure variables were derived by post-processing of the data using the built-in routines in AcqKnowledge. Left ventricular end-diastolic pressure was determined by identifying the peak of the second derivative of the pressure curve during each pressure waveform. Results were derived from all pressure waveforms during 4-6 consecutive respiratory cycles (corresponding to approximately 25-40 pressure waveforms) for each animal and average values are presented.

Left ventricular fibrosis (group A). The LV was immediately immersion fixed in $4 \%$ neutrally buffered formaldehyde (Histolab Products AB, Gothenburg, Sweden) for 5-7 days after which it was stored in 70\% ethanol at $4^{\circ} \mathrm{C}$ until further processing. Subsequently, the $\mathrm{LV}$ was cut transversally into base, middle, and apical parts and was dehydrated and embedded in paraffin. Using routine techniques, $3-\mu \mathrm{m}$ thick transverse sections were prepared and stained with hematoxylin and eosin, or Picrosirius red. 


\section{Kidney Blood Pressure Research}

Kidney Blood Press Res 2018;43:1053-1064

\begin{tabular}{l|l}
\hline DOI: $10.1159 / 000491056$ & (C) 2018 The Author(s). Published by S. Karger AG, Basel
\end{tabular}

Published online: 2 July, 2018

www.karger.com/kbr

1056

Morphometric analyses of LV fibrosis were performed as previously described in detail [13]. In brief, images of sections stained with Picrosirius red were derived using an Olympus BX60 microscope (camera Olympus DP72) and the imaging software cellSens (Olympus). The imaging software BioPix iQ 2.0 (BioPix, Gothenburg, Sweden) was used to objectively measure general and perivascular fibrosis. To correct for vessel size, perivascular fibrosis is expressed as fibrotic area per artery outer diameter [14]. The average number of LV arteries examined per individual was 15 with an average outer diameter of $87 \pm 9 \mu \mathrm{m}$. All assessments were made by an investigator blinded to rat identity.

Study group B ( $n=10$ per group), cardiomyocyte hypertrophy, apoptosis and proliferation

Rats were killed by decapitation 10 weeks after study start and the heart was immediately excised and the LV immersion fixed and processed as described above. Using routine techniques transverse sections were prepared from all three parts (base, middle, and apical) of the LV. Images of sections were derived using an Olympus BX60 microscope as described above and measurements were made using the software BioPix iQ 2.0 by an investigator blinded for rat identity.

Left ventricular cardiomyocyte hypertrophy (group B). Cardiomyocyte hypertrophy was determined on sections stained with fluoresceinisothiocyanate (FITC)-conjugated wheat germ agglutinin (WGA, Vector Laboratories, Burlingame, CA, USA) to delineate the cell membrane, and with DAPI (Vectashield mounting medium, Vector Laboratories, Burlingame, CA, USA) to visualize cell nuclei. Sections were permeabilisized using $0.1 \%$ Triton before being incubated with FITC-conjugated WGA $(0.5 \mathrm{mg} / \mathrm{ml})$ for 30 minutes in room temperature. From each level of the $\mathrm{LV}$ two sections were examined from each rat and a magnification $\mathrm{x} 40$ was used. A total number of 50 longitudinally oriented cardiomyocytes, with well-defined cell membranes, and visible cell nuclei, were analyzes in each rat. The cell diameter was measured through the cell nuclei and was used a measure of cell size.

Left ventricular apoptosis and proliferation (group B). Apoptotic cells were detected in situ on paraffinembedded sections by the terminal deoxynucleotidyl transferase dUTP nick end labeling (TUNEL) method using the ApopTag peroxidase in situ apoptosis detection kit according to the manufacturer's instructions (Merck KGaA, Darmstadt, Germany). For TUNEL detection the DAB peroxidase substrate kit (SK-4100, Vector Laboratories, Burlingame, CA, USA) was used.

Proliferating cells were detected on paraffin-embedded sections by immunohistochemistry using a mouse monoclonal anti-proliferating cell nuclear antigen (PCNA) antibody (ab 29, Abcam, Cambridge, UK). Heat-mediated antigen retrieval was performed using a citrate buffer $0.01 \mathrm{M}$. Sections were incubated with primary antibody using a 1:5000 dilution for 80 minutes in room temperature. For detection the MACH 3 mouse alkaline phosphatase polymer kit was used with Vulcan Fast Red as chromogen (M3M53G, Biocare Medical, Concord, CA, USA).

From each level of the LV one section was examined for apoptosis, and proliferation, respectively, from each rat. The number of TUNEL-positive cells, and PCNA-positive cells, were counted in 10 randomly selected visual fields using a 20x magnification. The total number of cardiomyocytes was also counted in sections stained by the TUNEL method and data on TUNEL-positive cells are presented as percent of positive cells in relation to the total amount of cardiomyocytes.

To verify that TUNEL-positive cells were apoptotic we examined if these cells also expressed cleaved caspase-3 by double immunohistochemistry staining on the same section. Paraffin-embedded sections from two rats were used and heat-mediated antigen retrieval was performed in a $0.01 \mathrm{M}$ citrate buffer. TUNEL staining was performed using the ApopTag Plus fluorescein in situ apoptosis detection kit (Chemicon, S7111) according to instructions. Subsequently sections were incubated with cleaved caspase- 3 antibody (ab 9661, Cell Signaling Technology, Danvers, MA, USA) using a 1:500 dilution for 60 minutes in room temperature. For detection, the DyLight 549 goat anti-rabbit IgG antibody kit was used (Vector Laboratories, Burlingame, CA, USA). Vectashield mounting medium with DAPI was used to visualize cell nuclei (H-1200, Vector Laboratories, Burlingame, CA, USA). Sections were analyzed by fluorescence microscopy using a three bands filter.

Study group C ( $n=8$ per group), Western blotting of LV tissue

Rats were sacrificed 10 weeks after study start. Following decapitation the heart was excised, cleaned, and the free wall of the left ventricle was flash-frozen, and stored at $-80^{\circ} \mathrm{C}$ until use. Tissue homogenization, 


\section{Kidney \\ Blood Pressure Research}

Kidney Blood Press Res 2018;43:1053-1064

\begin{tabular}{l|l}
\hline DOI: $10.1159 / 000491056$ & (C) 2018 The Author(s). Published by S. Karger AG, Basel
\end{tabular}

Published online: 2 July, 2018

www.karger.com/kbr

protein preparation and Western blotting were carried out as previously described in detail [15]. The primary antibodies employed were rabbit anti-collagen-1 alpha-1 (COL1A1), rabbit anti-intercellular adhesion molecule-1 (ICAM-1), rabbit anti-vascular cell adhesion molecule-1 (VCAM-1), rabbit anti-sodium-calcium exchanger-1 (NCX-1) and rabbit anti-glyceraldehyde 3-phosphate dehydrogenase (GAPDH), all from Santa Cruz Biotechnology, Texas, USA). Additional primary antibodies were rabbit anti-monocyte chemotactic protein-1 (MCP-1, Nordic Biosite AB, Stockholm, Sweden), and rabbit anti-bone morphogenetic protein-4 (BMP4) and mouse anti-sarcoplasmic reticulum $\mathrm{Ca}^{2+}$-ATPase (SERCA2), both from Abcam, Cambridge, UK.

Imaging analysis was performed using Image Lab 5 software (Bio-Rad) and values were normalized to GAPDH as an internal control. Results are presented as relative abundance and are expressed as fraction of control values within the same membrane.

\section{Biochemical analyses}

Plasma concentrations of creatinine, sodium, potassium, calcium and phosphate were determined by a Modular P800 Cobas C 701/502 analyzer (Roche/Hitachi, Roche Diagnostics GmbH, Mannheim, Germany).

\section{Statistics}

All values are means \pm SD. Differences between means were analyzed using paired or un-paired Student's t-test where appropriate and a significance level of $5 \%$ was used. Bonferroni correction was used to correct for multiple comparisons where appropriate. Chi-square test was used for categorical data. Statistical analyses were performed with GraphPad Prism v. 5.03 (San Diego, CA, USA) and SPSS 17.0 (SPSS Inc., Chicago, Illinois, USA).

\section{Statement of Ethics}

This study was performed on rats, and all experiments were approved by the regional ethics committee in Gothenburg, Sweden.

\section{Results}

\section{Kidney function and general characteristics (Table 1)}

Left ventricular weight was significantly elevated in ACRF rats whereas there were no statistically significant differences between groups in body weight or right ventricular weight.

Plasma concentrations of creatinine and potassium were clearly elevated in ACRF rats. There were no statistically significant differences between groups regarding plasma concentrations of sodium, calcium or phosphate.

Echocardiography of LV morphology and function (Table 2)

Stroke volume and cardiac output were significantly elevated in ACRF rats vs. controls. Left ventricular ejection fraction $(\mathrm{p}=0.053)$ and fractional shortening $(\mathrm{p}=0.055)$ were not significantly different between groups although values were numerically elevated in ACRF rats vs. controls. Left ventricular end-diastolic diameter did not differ significantly between groups. However, end-systolic diameter was significantly reduced in ACRF rats vs. controls. Thickness of the LV anterior wall was significantly elevated
Table 1. Organ weights and blood analyses at time of sacrifice. Values are means \pm SD. Data are from pair-fed control rats (controls) and rats with adenine-induced chronic renal failure (ACRF) 12-13 weeks after study start (protocol A, see Methods). BW, body weight; LVW, left ventricular weight; RVW, right ventricular weight. *** denotes $\mathrm{P}<0.001$

\begin{tabular}{lcc}
\hline Variable & Controls $(\mathrm{n}=10)$ & ACRF $(\mathrm{n}=10)$ \\
\hline BW $(\mathrm{g})$ & $359 \pm 19$ & $343 \pm 19$ \\
Tibia length $(\mathrm{mm})$ & $39.4 \pm 0.5$ & $39.9 \pm 1.4$ \\
LVW/tibia $(\mathrm{mg} / \mathrm{mm})$ & $22.5 \pm 2.2$ & $29.5 \pm 2.4^{* * *}$ \\
RVW/tibia $(\mathrm{mg} / \mathrm{mm})$ & $5.3 \pm 1.1$ & $5.7 \pm 1.0$ \\
P-creatinine $(\mu \mathrm{mol} / \mathrm{L})$ & $33 \pm 5$ & $323 \pm 107^{* * *}$ \\
P-sodium $(\mathrm{mmol} / \mathrm{L})$ & $144 \pm 3$ & $142 \pm 4$ \\
P-potassium $(\mathrm{mmol} / \mathrm{L})$ & $4.2 \pm 0.3$ & $6.3 \pm 0.7 * * *$ \\
P-calcium $(\mathrm{mmol} / \mathrm{L})$ & $2.42 \pm 0.10$ & $2.28 \pm 0.32$ \\
P-phosphate $(\mathrm{mmol} / \mathrm{L})$ & $1.7 \pm 0.1$ & $2.5 \pm 1.4$ \\
\hline
\end{tabular}




\section{Kidney \\ Blood Pressure Research}

Kidney Blood Press Res 2018;43:1053-1064

\begin{tabular}{l|l}
\hline DOI: $10.1159 / 000491056$ & (C) 2018 The Author(s). Published by S. Karger AG, Basel
\end{tabular}

Published online: 2 July, 2018 www.karger.com/kb in ACRF rats vs. controls indicating LV hypertrophy.

Echocardiographic indices of diastolic function and tissue Doppler velocities Rats with ACRF showed a significant decrease in e, and an increase in a, resulting in a marked decrease in the e/a ratio, vs. controls (Table 3 ). In addition, the $\mathrm{E} / \mathrm{e}$ ratio and left atrial diameter measured at the end of systole were both significantly elevated in ACRF rats indicating LV diastolic dysfunction (Fig. 1). There was no statistical significant difference between groups in LV tissue velocity during systole (s) (Table 3 ).

\section{Left ventricular and aortic pressures (Table 4)}

Systolic pressure, and pulse pressure, in the ascending aorta were significantly elevated in ACRF rats vs. controls. Both LV end-diastolic pressure (LVEDP) and LV systolic blood pressure (LVSBP) were significantly elevated in ACRF rats vs. controls. Maximal rates of LV pressure change during systole (dp/dt max), and diastole $(\mathrm{dp} / \mathrm{dt}$ min) were both significantly increased in ACRF rats vs. controls.

\section{Left ventricular morphology (Table 5)}

There were statistically significant increases in cardiomyocyte diameter (Fig. 2), and in the number of PCNA-positive (Fig. 3) and TUNEL-positive cells in the LV of ACRF rats vs. controls, while there was no statistically significant difference between groups regarding fibrosis. PCNA-positive cells were mainly localized adjacent to the microvasculature and in between cardiomyocytes indicating that proliferating cells were predominantly noncardiomyocytes (Fig. 3). TUNEL-staining and cleaved caspase- 3 co-localized in cardiomyocytes clearly indicating that these cells were undergoing apoptosis (Supplemental Fig. 1 and 2). For all supplemental material see www.karger.com/ doi/10.1159/000491056.

\section{Left ventricular proteins (Western blotting)}

There were no statistically significant differences between groups in protein levels of COL1A1, MCP-1, ICAM-1, VCAM-1, BMP-4, SERCA-1 or NCX-1 (Supplemental Fig. 3-5).
Table 3. Echocardiographic indices of diastolic function and tissue-Doppler velocities. Values are means \pm SD. Data from pair-fed control rats (controls) and rats with adenine-induced chronic renal failure (ACRF). Cardiac function was assessed by echocardiography 9 weeks after study start in rats anesthetized by isoflurane (see Methods). E, early diastolic filling velocity; A, filling velocity at atrial contraction; e, early diastolic tissue velocity; a, diastolic tissue velocity at atrial contraction; IVRT, isovolumetric relaxation time; and $\mathrm{s}$, systolic tissue velocity. ${ }^{* *}$ denotes $\mathrm{P}<0.01$

\begin{tabular}{lcc}
\hline Parameter & Controls $(\mathrm{n}=10)$ & ACRF $(\mathrm{n}=10)$ \\
\hline $\mathrm{E}(\mathrm{m} / \mathrm{s})$ & $0.94 \pm 0.08$ & $1.01 \pm 0.17$ \\
$\mathrm{~A}(\mathrm{~m} / \mathrm{s})$ & $0.86 \pm 0.10$ & $0.89 \pm 0.17$ \\
$\mathrm{E} / \mathrm{A}$ & $1.10 \pm 0.08$ & $1.21 \pm 0.43$ \\
$\mathrm{e}(\mathrm{cm} / \mathrm{s})$ & $7.2 \pm 1.4$ & $5.7 \pm 0.6^{* *}$ \\
$\mathrm{a}(\mathrm{cm} / \mathrm{s})$ & $5.5 \pm 1.4$ & $7.9 \pm 1.6^{* *}$ \\
$\mathrm{e} / \mathrm{a}$ & $1.4 \pm 0.5$ & $0.8 \pm 0.3^{* *}$ \\
$\mathrm{IVRT}(\mathrm{ms})$ & $19.7 \pm 1.5$ & $20.5 \pm 4.6$ \\
$\mathrm{~s}(\mathrm{~cm} / \mathrm{s})$ & $8.7 \pm 1.3$ & $8.8 \pm 1.3$ \\
\hline
\end{tabular}




\section{Kidney Blood Pressure Research}

Fig. 1. Indices of left ventricular diastolic function by echocardiography. Values are means \pm SD. Data from pair-fed control rats (controls) and rats with adenine-induced chronic renal failure (A-CRF). Cardiac morphology and function were assessed by echocardiography 9 weeks after study start in rats anesthetized by isoflurane (see

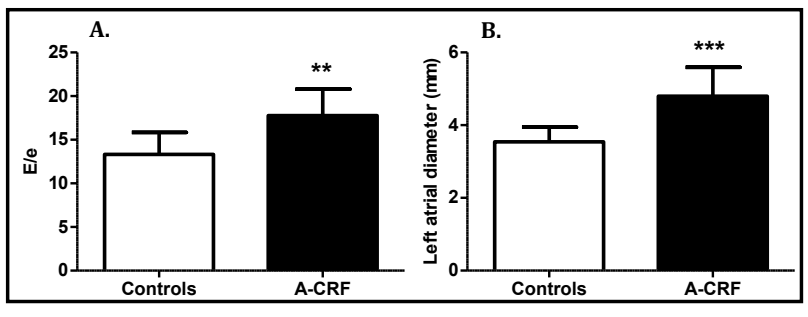
Methods). E, mitral blood flow velocity during early filling; and e, early diastolic tissue velocity of the basal left ventricle. Left atrial diameter was measured at end-systole. ${ }^{* *} \mathrm{P}<0.01$; ${ }^{* * *} \mathrm{P}<0.001$.

Table 4. Pressures in the ascending aorta and left ventricle. Values are means \pm SD. Data from pairfed control rats (controls) and rats with adenineinduced chronic renal failure (ACRF) at 12-13 weeks after study start (see Methods). SBP, systolic blood pressure; DBP, diastolic blood pressure; $\mathrm{PP}$, pulse pressure; MAP, mean arterial pressure; LVEDP, left ventricular end diastolic pressure; LVSBP, left ventricular systolic blood pressure; LVDBP, left ventricular diastolic blood pressure; $\mathrm{dp} / \mathrm{dt}$ max, maximal rate of pressure increase in the left ventricle; $\mathrm{dp} / \mathrm{dt}$ min, minimal rate of pressure increase in the left ventricle. ${ }^{*} \mathrm{P}<0.05$, ** $\mathrm{P}<0.01,{ }^{* * *} \mathrm{P}<0.001$

\begin{tabular}{lcc}
\hline Parameter & Controls $(\mathrm{n}=10)$ & ACRF $(\mathrm{n}=8)$ \\
\hline Heart rate $(\mathrm{bpm})$ & $353 \pm 25$ & $342 \pm 24$ \\
Ascending aortic SBP (mmHg) & $128 \pm 7$ & $140 \pm 7^{* *}$ \\
Ascending aortic DBP (mmHg) & $90 \pm 7$ & $91 \pm 7$ \\
Ascending aortic PP (mmHg) & $37 \pm 6$ & $49 \pm 2^{* * *}$ \\
Ascending aortic MAP (mmHg) & $103 \pm 6$ & $108 \pm 7$ \\
LVEDP (mmHg) & $8 \pm 1$ & $15 \pm 5^{* * *}$ \\
LVSBP peak (mmHg) & $125 \pm 6$ & $138 \pm 10^{* *}$ \\
LVDBP min (mmHg) & $-1.7 \pm 0.9$ & $-3.2 \pm 2.5$ \\
dp/dt max (mmHg/s) & $7428 \pm 624$ & $9529 \pm 2331^{*}$ \\
dp/dt min (mmHg/s) & $-9615 \pm 890$ & $-10637 \pm 746^{*}$ \\
\hline
\end{tabular}

Table 5. Left ventricular histology. Values are means \pm SD. Data from pair-fed control rats (controls) and rats with adenine-induced chronic renal failure (ACRF) at the time of sacrifice (see METHODS). PCNA, proliferating cell nuclear antigen. ${ }^{* *}$ denotes $\mathrm{P}<0.01$

\begin{tabular}{lcc}
\hline Parameter & $\begin{array}{c}\text { Controls } \\
(\mathrm{n}=10)\end{array}$ & $\begin{array}{c}\text { ACRF } \\
(\mathrm{n}=10)\end{array}$ \\
\hline Cardiomyocyte diameter $(\mu \mathrm{m})$ & $14.58 \pm 0.96$ & $17.36 \pm 2.17^{* *}$ \\
Number of PCNA positive cells & $8.30 \pm 5.17$ & $41.40 \pm 35.29^{* *}$ \\
Perivascular fibrosis/diameter $(\mu \mathrm{m})$ & $80.7 \pm 14.9$ & $88.5 \pm 16.9$ \\
General fibrosis, \% & $2.25 \pm 0.56$ & $2.35 \pm 0.91$ \\
Number of TUNEL positive cells $(\%)$ & $0.34 \pm 0.22$ & $1.57 \pm 1.20^{* *}$ \\
\hline
\end{tabular}

Fig. 2. Left ventricular cardiomyocyte hypertrophy in A-CRF rats. Left panels show left ventricular (LV) tissue from pair-fed controls and right panels from rats with adenine-induced chronic renal failure (A-CRF). Upper panels show immunofluorescence staining with FITCconjugated wheatgerm agglutinin (green) to delineate the cell membrane, and with DAPI (light blue) to visualize cell nuclei. Lower panels display longitudinally organized cardiomyocytes without immunostaining. Cardiomyocytes from A-CRF rats had an increased diameter indicating hypertrophy (numerical data are presented in Table 5). Magnifications were $\mathrm{x} 20$.

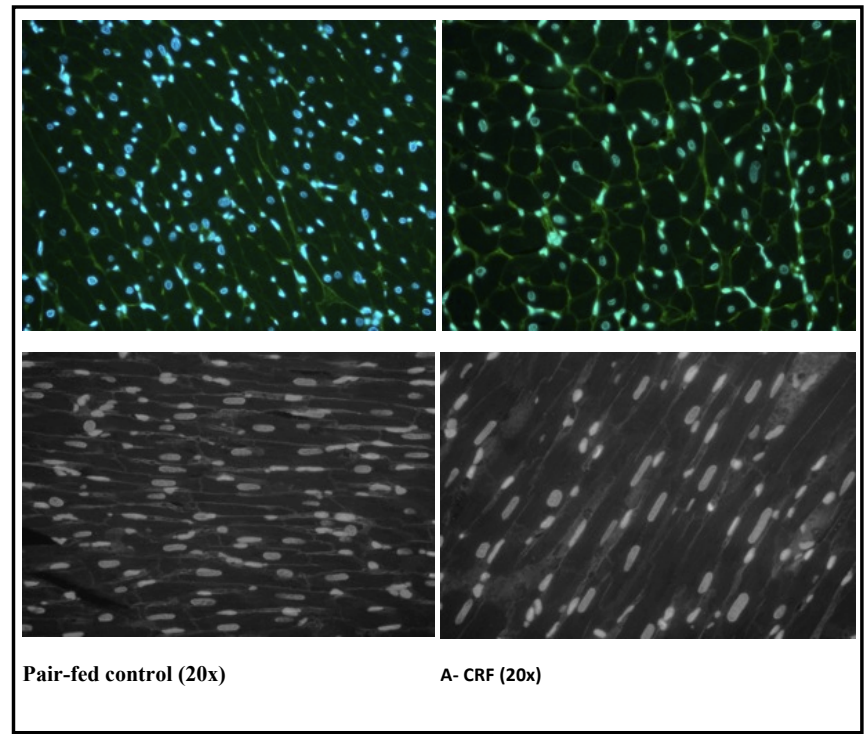




\section{Kidney \\ Blood Pressure Research}

Kidney Blood Press Res 2018;43:1053-1064

\begin{tabular}{l|l}
\hline DOI: $10.1159 / 000491056$ & (C) 2018 The Author(s). Published by S. Karger AG, Basel
\end{tabular}

Published online: 2 July, 2018 www.karger.com/kbr

Fig. 3. Immunohistochemistry for proliferating cell nuclear antigen (PCNA) in the left ventricle. Proliferating cells were detected by immunohistochemistry using a mouse monoclonal anti- PCNA antibody (see Methods). In controls the number of PCNA-positive cells was very few. In rats with adenine-induced chronic renal failure (A-CRF) PCNA-positive cells (red) were mainly localized adjacent to the microvasculature and in between cardiomyocytes indicating that these cells were predominantly non-cardiomyocytes (see arrows Fig. 2C). Numerical data are presented in Table 5.

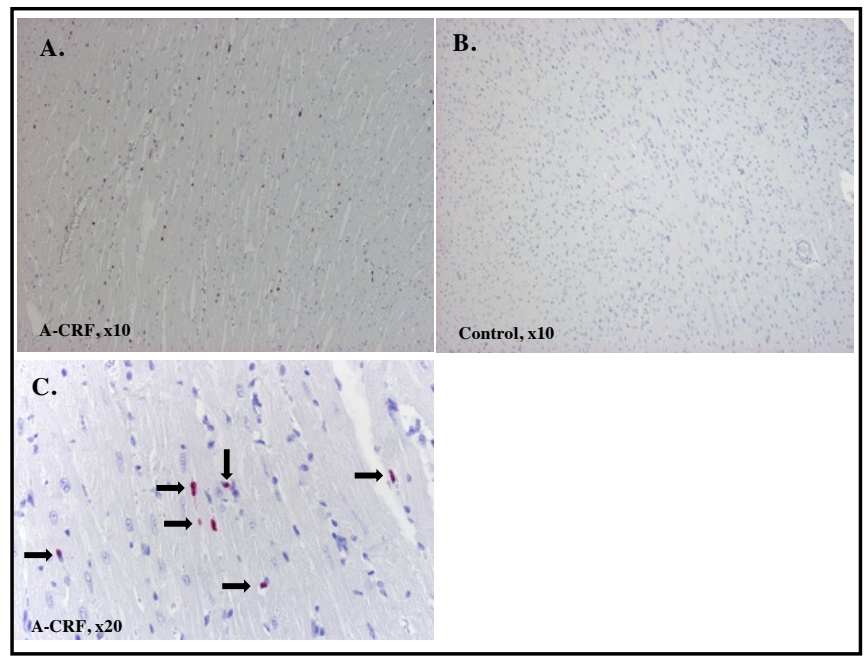

\section{Discussion}

The main finding in the present study was that rats with ACRF developed LV diastolic dysfunction although systolic function was preserved and cardiac output even elevated compared to controls with normal kidney function. In addition, rats with ACRF showed cardiomyocyte hypertrophy, and increased apoptosis in the LV. The cardiac phenotype in ACRF rats resembles heart failure with preserved ejection fraction (HFpEF) that is a common disorder in patients with CKD [16]. Hence, this experimental model seems to be well suited for investigating pathophysiological mechanisms of heart failure in CKD.

The clinical relevance of the ACRF model is supported by studies demonstrating a high prevalence of CKD in patients with HFpEF $[16,17]$. Furthermore, patients with early stages of CKD specifically develop signs of LV diastolic dysfunction prior to the onset of clinical heart failure manifestations [18] suggesting that reduced GFR may contribute to the development of HFpEF. Although the LV abnormalities described in the present study show resemblances to those observed in rats or mice with CKD caused by 5/6 nephrectomy [19-21] the ACRF model may have several advantages in addition to not requiring surgery. Rats subjected to $5 / 6$ nephrectomy typically develop only a relatively modest decrease GFR and consequently secondary metabolic changes such as alterations in mineral and bone metabolism are not as pronounced as in ACRF rats [19, 22-24]. In addition, severe hypertension is a characteristic feature of most 5/6 nephrectomy models $[23,25]$, which makes it difficult to distinguish whether cardiovascular abnormalities are primarily caused by high blood pressure or reduced kidney function.

The increase in cardiac output in ACRF rats was mainly a consequence of elevated stroke volume as heart rate was unaltered. In previous studies we have demonstrated that hypertensive ACRF rats have markedly reduced GFR and suppressed plasma renin levels [12], suggesting that they are volume expanded. However, in the present study echocardiography revealed that LVEDd was unchanged, whereas LVESd tended to be reduced, in ACRF rats compared to controls. This observation indicates that LV stroke volume was elevated largely due to enhanced contractility and not caused by increased end-diastolic filling volumes. In support of this notion, $\mathrm{LV} \mathrm{dp/dt} \mathrm{max} \mathrm{was} \mathrm{significantly} \mathrm{increased} \mathrm{in} \mathrm{ACRF} \mathrm{rats.} \mathrm{We} \mathrm{have}$ previously demonstrated that ACRF rats have anemia [5], which may cause a hyperdynamic circulation by increasing stroke volume [26]. A number of studies have shown that chronic renal failure is associated with sympathetic activation [27] and it is possible that elevated cardiac sympathetic nerve activity contributed to increased inotropy and elevated stroke volume. The mechanisms causing the increased contractility clearly need to be investigated further. In accord with our results Diwan et al. [28] showed in a similar model that male ACRF rats developed LV hypertrophy with preserved EF measured by echocardiography. 


\section{Kidney Blood Pressure Research}

Kidney Blood Press Res 2018;43:1053-1064

\begin{tabular}{l|l}
\hline DOI: $10.1159 / 000491056$ & (C) 2018 The Author(s). Published by S. Karger AG, Basel
\end{tabular}

Published online: 2 July, 2018

www.karger.com/kbr

1061

Interestingly, female rats subjected to an identical adenine-diet showed a different cardiac phenotype with eccentric LV hypertrophy and reduced EF [28]. However, these gender differences in LV morphology and function were likely explained by the fact that female ACRF rats developed a much less severe renal injury, and less pronounced hypertension, compared to male ACRF rats.

Together, our echocardiographic data and invasive LV pressure measurements indicate that LV diastolic function was impaired in ACRF rats. Using tissue Doppler imaging, rats with ACRF showed a significant reduction in early diastolic annular velocity, e. In addition, the E/e ratio was significantly elevated in ACRF rats suggesting increased diastolic filling pressures. Left ventricular pressure recordings confirmed that LVEDP was significantly elevated in ACRF rats. In accord with these data, left atrial diameter was increased in ACRF rats indicative of chronic diastolic dysfunction and a prolonged elevation in filling pressure [29]. Notably, ACRF rats did not have an increase in LVEDd suggesting that the increase in LV filling pressure was not caused by elevated diastolic volume, but rather by decreased tissue compliance. Rats with ACRF had increased LV weights and morphometric analysis revealed cardiomyocyte hypertrophy. Cardiomyocyte hypertrophy may be directly linked to decreased LV compliance and diastolic dysfunction [30]. In different animal models of LVH isolated cardiomyocytes have shown impairments in cytosolic calcium handling during diastole that may slow relaxation [30,31]. Interestingly, we have previously demonstrated a decreased relaxation rate in thoracic aortas of rats with ACRF [15]. Further analyses showed that intracellular $\mathrm{Ca}^{2+}$ handling was altered in vascular smooth muscle cells (VSMCs) of thoracic aortas and associated with abnormal expression of proteins involved in VSMC cytosolic $\mathrm{Ca}^{2+}$ clearance such as SERCA2 [15]. However, in contrast to our findings in thoracic aortas, the expression of SERCA2 was not significantly reduced in the LV of ACRF rats in the present study. Furthermore, and somewhat surprisingly, $\mathrm{LV} \mathrm{dp/dt} \mathrm{min} \mathrm{was} \mathrm{actually} \mathrm{increased}$ in ACRF rats suggesting an enhanced LV relaxation rate. Hence, different mechanisms seem to be responsible for the decreased relaxation rate in the thoracic aorta, and LV diastolic dysfunction, in ACRF rats. We believe that our data on LV dp/dt should be interpreted with caution considering that both preload and afterload may have substantial effects on this variable [32].

We hypothesized that ACRF rats might have increased LV fibrosis and that this contributed to diastolic dysfunction. We have previously shown that plasma aldosterone, which exerts pro-fibrotic effects [33, 34] is significantly elevated in ACRF rats [5]. However, using careful morphometrical analyses we did not detect a significant difference between groups in LV fibrosis in the present study. This is in agreement with our previous results in ACRF rats on a normal dietary $\mathrm{NaCl}$ intake [13]. In line with the histological data, $\mathrm{LV}$ protein expression of COL1A1 was not significantly increased in ACRF rats. Furthermore, levels of ICAM-1, VCAM-1 and BMP4, proteins known to be involved in LV inflammation and fibrosis $[35,36]$, were also not significantly altered in the LV of ACRF rats in the present study. Hence, LV diastolic dysfunction in ACRF rats was not explained by enhanced tissue fibrosis.

Presumably, hemodynamic mechanisms, such as elevated LV afterload, were a major cause of LVH in ACRF rats. Systolic blood pressure in the ascending aorta was significantly elevated and we have previously shown that ACRF rats have an increased aortic PWV [12]. However, several non-hemodynamic factors have also been suggested to cause LVH in CKD, e.g. aldosterone [33, 34] and fibroblast growth factor-23 [37], which both are elevated in the ACRF model $[5,38]$. In addition to hypertrophy, there was a marked increase in LV cell proliferation in ACRF rats $(\approx 5$-fold increase in the number of PCNA-positive cells vs. controls). However, PCNA-positive cells were mainly localized in the surrounding of the microvasculature, and in between cardiomyocytes, clearly indicating that proliferating cells were non-cardiomyocytes and presumably fibroblasts or inflammatory cells.

Our finding of an increased apoptosis of cardiomyocytes in the LV of ACRF rats is corroborated by similar results in other experimental CKD models [39, 40]. Martin et al. [39] found increased apoptosis, and marked alterations in the expression of genes regulating 


\section{Kidney \\ Blood Pressure Research}

Kidney Blood Press Res 2018;43:1053-1064

\begin{tabular}{l|l}
\hline DOI: $10.1159 / 000491056$ & (C) 2018 The Author(s). Published by S. Karger AG, Basel
\end{tabular}

Published online: 2 July, 2018

www.karger.com/kbr

apoptosis by microarray analysis, in the LV of rats with mild kidney dysfunction caused by unilateral nephrectomy [39]. The mechanisms causing LV apoptosis in CKD are yet to be defined but are likely multifactorial.

\section{Conclusion}

ACRF rats developed LV hypertrophy and diastolic dysfunction with preserved systolic function. These abnormalities resemble LV dysfunctions in patients with CKD in which HFpEF is common. Hence, the ACRF model seems to be suitable for investigating pathophysiological mechanisms leading to heart failure in CKD.

\section{Acknowledgements}

The technical assistance of Mohamed Ibrahim is acknowledged.

This study was supported by grants from the Swedish Heart-Lung Foundation, Swedish Federal Government under the LUA/ALF agreement, Göteborg Medical Society, Swedish Medical Society, Swedish Association for Kidney Patients, Swedish Society of Nephrology, Inger Bendix Foundation, Paul Frankenius Foundation, Britt Wennerström's Research Foundation and IngaBritt and Arne Lundbergs Research Foundation.

\section{Disclosure Statement}

No conflicts of interest, financial or otherwise, are declared by the authors.

\section{References}

1 Foley RN, Parfrey PS, Sarnak MJ: Clinical epidemiology of cardiovascular disease in chronic renal disease. Am J Kidney Dis 1998;32:S112-119.

2 Go AS, Chertow GM, Fan D, McCulloch CE, Hsu CY: Chronic kidney disease and the risks of death, cardiovascular events, and hospitalization. N Engl J Med 2004;351:1296-1305.

3 Sarnak MJ, Levey AS, Schoolwerth AC, Coresh J, Culleton B, Hamm LL, McCullough PA, Kasiske BL, Kelepouris E, Klag MJ, Parfrey P, Pfeffer M, Raij L, Spinosa DJ, Wilson PW, American Heart Association Councils on Kidney in Cardiovascular Disease HBPRCC, Epidemiology, Prevention: Kidney disease as a risk factor for development of cardiovascular disease: A statement from the american heart association councils on kidney in cardiovascular disease, high blood pressure research, clinical cardiology, and epidemiology and prevention. Circulation 2003;108:2154-2169.

4 Gansevoort RT, Correa-Rotter R, Hemmelgarn BR, Jafar TH, Heerspink HJ, Mann JF, Matsushita K, Wen CP: Chronic kidney disease and cardiovascular risk: Epidemiology, mechanisms, and prevention. Lancet 2013;382:339-352.

5 Nguy L, Nilsson H, Lundgren J, Johansson ME, Teerlink T, Scheffer PG, Guron G: Vascular function in rats with adenine-induced chronic renal failure. Am J Physiol Regul Integr Comp Physiol 2012;302:R1426-1435.

6 Yokozawa T, Zheng PD, Oura H, Koizumi F: Animal model of adenine-induced chronic renal failure in rats. Nephron 1986;44:230-234.

7 Neven E, Dauwe S, De Broe ME, D’Haese PC, Persy V: Endochondral bone formation is involved in media calcification in rats and in men. Kidney Int 2007;72:574-581.

$>8$ Lomashvili KA, Monier-Faugere MC, Wang X, Malluche HH, O’Neill WC: Effect of bisphosphonates on vascular calcification and bone metabolism in experimental renal failure. Kidney Int 2009;75:617-625. 


\section{Kidney \\ Blood Pressure Research}

Kidney Blood Press Res 2018;43:1053-1064

\begin{tabular}{l|l}
\hline DOI: $10.1159 / 000491056$ & (C) 2018 The Author(s). Published by S. Karger AG, Basel
\end{tabular}

Published online: 2 July, 2018 www.karger.com/kbr

-9 Nagano N, Miyata S, Abe M, Kobayashi N, Wakita S, Yamashita T, Wada M: Effect of manipulating serum phosphorus with phosphate binder on circulating pth and fgf23 in renal failure rats. Kidney Int 2006;69:531-537.

10 Tang MS, Haugen E, Isic A, Fu M, Andersson B: Influence of age, hypertension, and diabetes on cardiac reserve in a rat model. J Am Soci Echocardiogr 2007;20:731-737.

11 Sahn DJ, DeMaria A, Kisslo J, Weyman A: Recommendations regarding quantitation in m-mode echocardiography: Results of a survey of echocardiographic measurements. Circulation 1978;58:10721083.

-12 Nguy L, Johansson ME, Grimberg E, Lundgren J, Teerlink T, Carlstrom M, Lundberg JO, Nilsson H, Guron G: Rats with adenine-induced chronic renal failure develop low-renin, salt-sensitive hypertension and increased aortic stiffness. Am J Physiol Regul Integr Comp Physiol 2013;304:R744-752.

-13 Kashioulis P, Hammarsten O, Marcussen N, Shubbar E, Saeed A, Guron G: High-NaCl diet aggravates cardiac injury in rats with adenine-induced chronic renal failure and increases serum troponin $t$ levels. Cardiorenal Med 2016;6:317-327.

14 Shi YX, Chen Y, Zhu YZ, Huang GY, Moore PK, Huang SH, Yao T, Zhu YC: Chronic sodium hydrosulfide treatment decreases medial thickening of intramyocardial coronary arterioles, interstitial fibrosis, and ROS production in spontaneously hypertensive rats. Am J Physiol Heart Circ Physiol 2007;293:H2093-2100.

15 Nguy L, Shubbar E, Jernas M, Nookaew I, Lundgren J, Olsson B, Nilsson H, Guron G: Adenine-induced chronic renal failure in rats decreases aortic relaxation rate and alters expression of proteins involved in vascular smooth muscle calcium handling. Acta Physiol Scand 2016;218:250-264.

16 Gori M, Senni M, Gupta DK, Charytan DM, Kraigher-Krainer E, Pieske B, Claggett B, Shah AM, Santos AB, Zile MR, Voors AA, McMurray JJ, Packer M, Bransford T, Lefkowitz M, Solomon SD, Investigators P: Association between renal function and cardiovascular structure and function in heart failure with preserved ejection fraction. Eur Heart J 2014;35:3442-3451.

17 Lofman I, Szummer K, Dahlstrom U, Jernberg T, Lund LH: Associations with and prognostic impact of chronic kidney disease in heart failure with preserved, mid-range, and reduced ejection fraction. Eur J Heart Fail 2017;19:1606-1614.

18 Edwards NC, Hirth A, Ferro CJ, Townend JN, Steeds RP: Subclinical abnormalities of left ventricular myocardial deformation in early-stage chronic kidney disease: The precursor of uremic cardiomyopathy? J Am Soci Echocardiogr 2008;21:1293-1298.

19 Primessnig U, Schonleitner P, Holl A, Pfeiffer S, Bracic T, Rau T, Kapl M, Stojakovic T, Glasnov T, Leineweber K, Wakula P, Antoons G, Pieske B, Heinzel FR: Novel pathomechanisms of cardiomyocyte dysfunction in a model of heart failure with preserved ejection fraction. Eur J Heart Fail 2016;18:987-997.

20 Bongartz LG, Braam B, Verhaar MC, Cramer MJ, Goldschmeding R, Gaillard CA, Doevendans PA, Joles JA: Transient nitric oxide reduction induces permanent cardiac systolic dysfunction and worsens kidney damage in rats with chronic kidney disease. Am J Physiol Regul Integr Comp Physiol 2010;298:R815-823.

-21 Kennedy DJ, Elkareh J, Shidyak A, Shapiro AP, Smaili S, Mutgi K, Gupta S, Tian J, Morgan E, Khouri S, Cooper CJ, Periyasamy SM, Xie Z, Malhotra D, Fedorova OV, Bagrov AY, Shapiro JI: Partial nephrectomy as a model for uremic cardiomyopathy in the mouse. Am J Physiol Renal Physiol 2008;294:F450-454.

-22 Michea L, Villagran A, Urzua A, Kuntsmann S, Venegas P, Carrasco L, Gonzalez M, Marusic ET: Mineralocorticoid receptor antagonism attenuates cardiac hypertrophy and prevents oxidative stress in uremic rats. Hypertension 2008;52:295-300.

-23 Di Marco GS, Reuter S, Kentrup D, Grabner A, Amaral AP, Fobker M, Stypmann J, Pavenstadt H, Wolf M, Faul C, Brand M: Treatment of established left ventricular hypertrophy with fibroblast growth factor receptor blockade in an animal model of CKD. Nephrol Dial Transplant 2014;29:2028-2035.

24 Shobeiri N, Adams MA, Holden RM: Vascular calcification in animal models of CKD: A review. Am J Nephrol 2010;31:471-481.

25 Bidani AK, Griffin KA, Bakris G, Picken MM: Lack of evidence of blood pressure-independent protection by renin-angiotensin system blockade after renal ablation. Kidney Int 2000;57:1651-1661.

-26 Klein HG, Spahn DR, Carson JL: Red blood cell transfusion in clinical practice. Lancet 2007;370:415-426.

27 Converse RL Jr, Jacobsen TN, Toto RD, Jost CM, Cosentino F, Fouad-Tarazi F, Victor RG: Sympathetic overactivity in patients with chronic renal failure. N Engl J Med 1992;327:1912-1918. 


\section{Kidney \\ Blood Pressure Research}

Kidney Blood Press Res 2018;43:1053-1064

\begin{tabular}{l|l}
\hline DOI: $10.1159 / 000491056$ & (C) 2018 The Author(s). Published by S. Karger AG, Basel
\end{tabular}

Published online: 2 July, 2018 www.karger.com $/ \mathrm{kbr}$

28 Diwan V, Small D, Kauter K, Gobe GC, Brown L: Gender differences in adenine-induced chronic kidney disease and cardiovascular complications in rats. Am J Physiol Renal Physiol 2014;307:F1169-1178.

29 Abhayaratna WP, Seward JB, Appleton CP, Douglas PS, Oh JK, Tajik AJ, Tsang TS: Left atrial size: Physiologic determinants and clinical applications. J Am Coll Cardiol 2006;47:2357-2363.

-30 Heinzel FR, Hohendanner F, Jin G, Sedej S, Edelmann F: Myocardial hypertrophy and its role in heart failure with preserved ejection fraction. J Appl Physiol 2015;119:1233-1242.

-31 McMahon AC, Naqvi RU, Hurst MJ, Raine AE, MacLeod KT: Diastolic dysfunction and abnormality of the $\mathrm{Na}+/ \mathrm{Ca} 2+$ exchanger in single uremic cardiac myocytes. Kidney Int 2006;69:846-851.

-32 Grossman W, Haynes F, Paraskos JA, Saltz S, Dalen JE, Dexter L: Alterations in preload and myocardial mechanics in the dog and in man. Circ Res 1972;31:83-94.

-33 Mule G, Nardi E, Guarino L, Cacciatore V, Geraci G, Calcaterra I, Oddo B, Vaccaro F, Cottone S: Plasma aldosterone and its relationship with left ventricular mass in hypertensive patients with early-stage chronic kidney disease. Hypertens Res 2015;38:276-283.

-34 Lu R, Zhang Y, Zhu X, Fan Z, Zhu S, Cui M, Zhang Y, Tang F: Effects of mineralocorticoid receptor antagonists on left ventricular mass in chronic kidney disease patients: A systematic review and meta-analysis. Int Urol Nephrol 2016;48:1499-1509.

35 Kuroda YT, Komamura K, Tatsumi R, Mori K, Yoneda K, Katayama Y, Shigemoto S, Miyatake K, Hanafusa T: Vascular cell adhesion molecule-1 as a biochemical marker of left ventricular mass in the patients with hypertension. Am J Hypertens 2001;14:868-872.

36 Sun B, Huo R, Sheng Y, Li Y, Xie X, Chen C, Liu HB, Li N, Li CB, Guo WT, Zhu JX, Yang BF, Dong DL: Bone morphogenetic protein-4 mediates cardiac hypertrophy, apoptosis, and fibrosis in experimentally pathological cardiac hypertrophy. Hypertension 2013;61:352-360.

-37 Faul C, Amaral AP, Oskouei B, Hu MC, Sloan A, Isakova T, Gutierrez OM, Aguillon-Prada R, Lincoln J, Hare JM, Mundel P, Morales A, Scialla J, Fischer M, Soliman EZ, Chen J, Go AS, Rosas SE, Nessel L, Townsend RR, et al.: Fgf23 induces left ventricular hypertrophy. J Clin Invest 2011;121:4393-4408.

-38 Verhulst A, Neven E, D’Haese PC: Characterization of an animal model to study risk factors and new therapies for the cardiorenal syndrome, a major health issue in our aging population. Cardiorenal Med 2017;7:234-244.

-39 Martin FL, McKie PM, Cataliotti A, Sangaralingham SJ, Korinek J, Huntley BK, Oehler EA, Harders GE, Ichiki T, Mangiafico S, Nath KA, Redfield MM, Chen HH, Burnett JC Jr: Experimental mild renal insufficiency mediates early cardiac apoptosis, fibrosis, and diastolic dysfunction: A kidney-heart connection. Am J Physiol Regul Integr Comp Physiol 2012;302:R292-299.

40 Amann K, Tyralla K, Gross ML, Schwarz U, Tornig J, Haas CS, Ritz E, Mall G: Cardiomyocyte loss in experimental renal failure: Prevention by ramipril. Kidney Int 2003;63:1708-1713. 